\title{
RESPON PERTUMBUHAN DAN HASIL BAWANG MERAH TERHADAP PUPUK KALSIUM NITRAT
}

\section{RESPONSE OF SHALLOT GROWTH AND YIELD TO CALSIUM NITRATE FERTILIZER}

\author{
Lina Aisyawati ${ }^{1)}$ dan Fuad Nur Azis ${ }^{1)}$ \\ ${ }^{1)}$ Balai Pengkajian Teknologi Pertanian (BPTP) Jawa Timur \\ Email: linasoil00@gmail.com
}

\begin{abstract}
ABSTRAK
Pengelolaan unsur hara Nitrogen $(\mathrm{N})$ melalui pemupukan yang cukup dan berimbang berperan penting untuk meningkatkan produktivitas bawang merah. Penggunaan senyawa nitrat sebagai sumber $\mathrm{N}$ dapat menjadi alternatif dalam penambahan unsur N. Penelitian ini bertujuan untuk mengetahui respon pertumbuhan dan hasil bawang merah pada beberapa taraf dosis pupuk kalsium nitrat. Penelitian dilakukan di Kebun Percobaan Mojosari, Kabupaten Mojokerto mulai Maret-Mei 2019. Penelitian menggunakan Rancangan Acak Kelompok diulang 3 kali menggunakan 9 perlakuan yaitu kontrol, dosis rekomendasi $(200 \mathrm{~kg} / \mathrm{ha}$ Urea dan 500 $\mathrm{kg} / \mathrm{ha}$ ZA), dosis kombinasi pemberian Urea, ZA, dan Kalsium Nitrat. Parameter yang diamati adalah tinggi tanaman, jumlah anakan, diameter umbi, bobot rumpun, bobot rumpun kering askip, susut bobot, dan produktivitas. Hasil penelitian menunjukkan bahwa perlakuan dosis $150 \mathrm{~kg} / \mathrm{ha}$ Urea dan $375 \mathrm{~kg} / \mathrm{ha}$ ZA ditambahkan dengan dosis $5 \mathrm{~g} / \mathrm{l}$ kalsium nitrat yang mampu meningkatkan pertumbuhan dan hasil tanaman bawang merah dibandingkan dengan perlakuan lainnya.
\end{abstract}

Kata Kunci: Bawang Merah; Dosis Rekomendasi; Nitrogen

\begin{abstract}
Nitrogen (N) nutrient management through adequate and balanced fertilization plays an important role in increasing the productivity of shallots. The use of nitrate compounds as a source of $N$ can be an alternative in the addition of the $N$ element. This study was aimed to determine the response of shallot growth and yield from several levels of calcium nitrate fertilizer. The research was conducted at the Mojosari Experimental Garden, Mojokerto Regency from March to May 2019. The study used a Randomized Block Design with 3 replicates. The study used 9 treatments namely control, recommended dosage (200 kg / ha Urea and $500 \mathrm{~kg} / \mathrm{ha} \mathrm{ZA),} \mathrm{the}$ combined dose of Urea, ZA, and calcium nitrate. The parameters observed were plant height, number of tillers, tuber diameter, weight of the clump, dry weight of the askip clump, weight loss, and productivity. The results showed that the treatment with dosage of $150 \mathrm{~kg} / \mathrm{ha}$ Urea and $375 \mathrm{~kg} / \mathrm{ha}$ ZA which was added with a dose of $5 \mathrm{~g} / \mathrm{l}$ calcium nitrate was able to increase the shallot growth and yield plants compared to other treatments.
\end{abstract}

Keywords: Nitrogen; Recommended Dosage; Shallot 


\section{PENDAHULUAN}

Pengelolaan hara yang optimal melalui pemupukan dapat meningkatkan produktivitas, kualitas hasil serta melestarikan tanah. Hara esensial makro dibutuhkan tanaman bawang merah dalam jumlah yang cukup dan berimbang sehingga tujuan pengelolaan hara dapat tercapai (Sumarni et al., 2016; Suwandi et al., 2017).

Nitrogen (N) merupakan unsur hara makro yang penting bagi tanaman bawang merah. Hara ini berperan dalam pengelolaan pembentuk enzim pada kloroplast. Tingginya asupan nitrogen pada tanaman akan meningkatkan laju pertumbuhan vegetatif karena meningkatnya aktivitas enzim pada kloroplas (Barker dan David J. Pilbeam, 2015). Defisiensi nitrogen pada tanaman terlihat jelas dari warna daun dan organ lainnya. Kurangnya kloroplas mengakibatkan tanaman tidak dapat berasimilasi dengan baik sehingga tidak mampu mensuplai energi ke seluruh jaringan lain. Hal ini menyebabkan tanaman tidak tumbuhan dan berkembang dengan optimal.

Pengelolaan hara $\mathrm{N}$ pada umumnya menggunakan senyawa berbentuk ammonium. Hal ini memiliki dampak negatif bagi pertanaman bawang merah karena ammonium sangat mudah digunakan oleh jamur sebagai salah satu organisme pengganggu tanaman bawang merah (Kurniasih, et al., 2017). Senyawa nitrat sebagai sumber $\mathrm{N}$ dapat menjadi alternatif dalam penambahan unsur N. Nitrat merupakan senyawa yang tidak mudah menguap sehingga dapat diaplikasikan melalui penyemprotan pada daun. Aplikasi nitrat di tanah berpotensi mengakibatkan kehilangan unsur nitrat yang tinggi karena nitrat akan menuju zona yang lebih dalam sedangkan perakaran bawang merah tergolong pendek (Sinaga, et al., 2014).

Pemberian pupuk dapat dilakukan melalui akar dan daun. Pemupukan melalui daun dapat menjaga pertumbuhan dan hasil tanaman dengan efisiensi pupuk rekomendasi yang diberikan di tanah 
(Alexander dan Schroeder, 1987).

Pupuk daun seperti $\mathrm{Ca}(\mathrm{NO} 3)_{2}$ pada tanaman hortikultura kentang dapat meningkatkan produksi umbi mini pada benih (Dianawati, et al., 2013). Dosis pupuk daun masih perlu dilakukan penelitian lebih lanjut karena terdapat perbedaan pengaruh pupuk daun pada beberapa penelitian yang telah dilakukan. Tujuan penelitian ini adalah untuk mengetahui respon pertumbuhan dan hasil bawang merah dari beberapa taraf dosis pupuk kalsium nitrat.

\section{METODE PENELITIAN}

Penelitian dilakukan di Kebun Percobaan Mojosari yang mempunyai ketinggian \pm 28 meter dpl. Lokasi KP Mojosari berada di Kecamatan
Mojosari Kabupaten Mojokerto. Lahan penelitian merupakan lahan sawah irigasi teknis dengan sumber air dapat berasal dari irigasi tersier dan pompa diesel. Posisi lahan berada di koordinat $7^{\circ} 30^{\prime 2} 27.6^{\prime \prime}$ Lintang Selatan, $112^{\circ} 31 ' 55.0^{\prime \prime}$ Bujur Timur. Penelitian dilakukan dari tanggal 23 Maret sampai dengan 27 Mei 2019. Penelitian dilakukan pada lahan dengan kondisi $\mathrm{N}$ dalam tanah yang rendah (Tabel 1). Penelitian menggunakan Rancangan Acak Kelompok diulang 3 kali dengan jumlah perlakuan sebanyak 9 perlakuan (0). Dosis rekomendasi pupuk Nitrogen yang digunakan adalah $200 \mathrm{~kg} / \mathrm{ha}$ Urea dan $500 \mathrm{~kg} / \mathrm{ha}$ ZA (Sumarni dan Hidayat, 2005).

Tabel 1. Analisis kesuburan tanah di lokasi penelitian

\begin{tabular}{lccl}
\hline Parameter uji & Nilai & Satuan & Kategori \\
\hline C-Organik & 0,98 & $\%$ & Sangat rendah \\
Nitrogen Total & 0,11 & $\%$ & Rendah \\
\hline
\end{tabular}

Keterangan: Kategori yang dilakukan berdasarkan Eviati dan Sulaeman (2009) diuji di Laboratorium Tanah BPTP Jawa Timur 
Tabel 2. Perlakuan dosis pupuk pada tanaman bawang merah

\begin{tabular}{clccccc}
\hline & & \multicolumn{3}{c}{ Dosis Pupuk } & \multicolumn{3}{c}{ Kandungan N Pupuk } \\
\cline { 3 - 7 } Kode Perlakuan & $\begin{array}{c}\text { Urea } \\
(\mathrm{kg} / \mathrm{ha}\end{array}$ & $\begin{array}{c}\mathrm{ZA} \\
(\mathrm{kg} / \mathrm{ha})\end{array}$ & $\begin{array}{c}\mathrm{KN} \\
(\mathrm{g} / \mathrm{l})\end{array}$ & $\begin{array}{c}\mathrm{N} \\
\text { tanah } \\
(\mathrm{kg} / \mathrm{ha})\end{array}$ & $\begin{array}{c}\mathrm{N} \text { daun } \\
\left.(\mathrm{ppm} \mathrm{NO})_{3}\right)\end{array}$ \\
\hline $\mathrm{A}$ & Kontrol & 0 & 0 & 0 & 0 & 0 \\
$\mathrm{~B}$ & Dosis rekomendasi & 200 & 500 & 0 & 197 & 0 \\
$\mathrm{C}$ & Dosis rekomendasi+2.5 g/l KN & 200 & 500 & 2.5 & 197 & 1027.5 \\
$\mathrm{D}$ & Dosis rekomendasi+5 g/l KN & 200 & 500 & 5 & 197 & 2055 \\
$\mathrm{E}$ & Dosis rekomendasi+10 g/l KN & 200 & 500 & 10 & 197 & 4110 \\
$\mathrm{~F}$ & 3/4 Dosis rekomendasi+5 g/l KN & 150 & 375 & 5 & 147.75 & 2055 \\
$\mathrm{G}$ & 1/2 Dosis rekomendasi+5 g/l KN & 100 & 250 & 5 & 98.5 & 2055 \\
$\mathrm{H}$ & 1/4 Dosis rekomendasi+5 g/l KN & 50 & 125 & 5 & 49.25 & 2055 \\
$\mathrm{~J}$ & 2x Dosis rekomendasi+5 g/l KN & 400 & 1000 & 5 & 394 & 2055 \\
\hline
\end{tabular}

Keterangan: $\mathrm{KN}=$ kalsium nitrat

Parameter yang diamati dalam penelitian ini adalah tinggi tanaman $(\mathrm{cm})$, jumlah anakan, diameter umbi $(\mathrm{cm})$, bobot rumpun $(\mathrm{g})$ bobot rumpun kering (g), susut bobot, dan produktivitas. Data yang diperoleh dianalisis menggunakan uji $\mathrm{F}$ pada taraf tingkat kesalahan 5\%. Variabel yang berpengaruh nyata diuji lanjut menggunakan BNJ 5\%.

\section{HASIL DAN PEMBAHASAN}

\section{Tinggi Tanaman}

Tinggi tanaman pada umur 14, 30, dan 60 HST menunjukkan kecenderungan yang sama (0).
Perlakuan kontrol; $1 / 2$ dosis rekomendasi+5 g/l kalsium nitrat; dan 1/4 dosis rekomendasi+5 g/l kalsium nitrat memiliki tinggi tanaman paling pendek dibandingkan dengan perlakuan lain. Pupuk anorganik kalsium nitrat dosis $5 \mathrm{~g} / \mathrm{l}$ dapat mengoptimalkan tinggi tanaman meskipun dosis pupuk dari urea dan ZA hanya diberikan sebanyak 3/4 dari dosis rekomendasi. Hal ini menunjukkan bahwa pemberian pupuk anorganik kalsium nitrat dapat menjadi pupuk pelengkap cair yang meningkatkan tinggi tanaman. 
Tabel 3. Pengaruh Pupuk Anorganik Kalsium Nitrat Terhadap Tinggi Tanaman

\begin{tabular}{llrrrrrrr}
\hline & \multirow{2}{*}{ Perlakuan } & \multicolumn{6}{c}{ Tinggi Tanaman $(\mathrm{cm})$} \\
\cline { 3 - 9 } & 7 HST & 14 HST & 30 HST & 60 HST \\
\hline A & Kontrol & 10,13 & 20,67 & c & 22,93 & c & 25,00 & c \\
B & Dosis rekomendasi & 9,87 & 25,67 & a & 28,93 & a & 31,87 & a \\
C & Dosis rekomendasi+2.5 g/l KN & 9,53 & 23,53 & b & 26,40 & b & 29,33 & b \\
D & Dosis rekomendasi+5 g/l KN & 10,07 & 25,93 & a & 29,20 & a & 32,13 & a \\
E & Dosis rekomendasi+10 g/l KN & 9,67 & 26,13 & a & 29,27 & a & 32,33 & a \\
F & 3/4 Dosis rekomendasi+5 g/l KN & 10,2 & 25,80 & a & 28,73 & a & 31,73 & a \\
G & 1/2 Dosis rekomendasi+5 g/l KN & 10,4 & 21,73 & c & 23,47 & c & 25,40 & c \\
H & 1/4 Dosis rekomendasi+5 g/l KN & 10,13 & 21,67 & c & 23,60 & c & 25,60 & c \\
J & 2x Dosis rekomendasi+5 g/l KN & 10,67 & 26,20 & a & 29,33 & a & 32,20 & a \\
\hline
\end{tabular}

Keterangan: $\mathrm{KN}=$ kalsium nitrat

Angka yang diikuti oleh huruf yang sama pada kolom yang sama tidak berbeda nyata pada uji BNJ 5\%

Tinggi tanaman bawang merah pada penelitian ini tergolong cukup pendek pada usia 60 HST. Rentang tinggi tanaman hanya berkisar antara $25 \mathrm{~cm}$ sampai $32 \mathrm{~cm}$ padahal varietas tajuk pada umur 50 hari di sentra bawang merah Nganjuk bisa mencapai 45,6 cm (Baswarsiati dan Tafakresnanto, 2019). Hal ini dikarenakan kandungan $\mathrm{N}$ total di lokasi penelitian yang berkategori rendah (Tabel 1). Hal tersebut menjadikan pengaruh penggunaan kalsium nitrat pada daun bersama beberapa taraf pemupukan menjadi jelas terlihat. Pada kondisi N tanah yang rendah menjadikan penggunaan pupuk kalsium nitrat $5 \mathrm{~g} / \mathrm{l}$ yang dikombinasikan dengan $3 / 4 \quad$ dosis rekomendasi mampu memicu pertumbuhan tinggi tanaman hingga sama dengan penggunaan pupuk dosis rekomendasi penuh.

\section{Jumlah Anakan}

Jumlah anakan pada umur 14, 30, dan 60 HST menunjukkan kecenderungan yang sama (0). Aplikasi pupuk kalsium nitrat dengan dosis 2,5 g/l sampai dengan $10 \mathrm{~g} / \mathrm{l}$ (perlakuan C, D, dan E) tidak menunjukkan perbedaan yang nyata dengan dosis rekomendasi (perlakuan B). Penurunan dosis pupuk rekomendasi (perlakuan F, G, dan $\mathrm{H}$ ) mengakibatkan penurunan jumlah anakan dibandingkan dosis rekomendasi (perlakuan B) (0). Hal itu 
menunjukkan bahwa jumlah anakan tidak dipengaruhi oleh pupuk kalsium nitrat. Jumlah anakan tanaman bawang merah menurut Sumarni, et al., (2016) lebih dipengaruhi oleh faktor genetik dibandingkan dengan unsur hara. Pengaruh unsur hara terhadap jumlah anakan akan terlihat apabila digunakan pada jarak tanam yang berbeda (Sumarni, et al., 2013) sehingga pengaruh $\mathrm{N}$ pada penelitian ini tidak terlihat pada jumlah anakan.

Tabel 4. Pengaruh Pupuk Anorganik Kalsium Nitrat Terhadap Jumlah Anakan

\begin{tabular}{clrrrrrrr}
\hline \multirow{2}{*}{ Kode } & \multirow{2}{*}{ Perlakuan } & \multicolumn{7}{c}{ Jumlah Anakan } \\
\cline { 3 - 9 } & & 7 HST & 14 HST & 30 HST & 60 HST \\
\hline A & Kontrol & 1,80 & 4,07 & $\mathrm{~b}$ & 5,07 & $\mathrm{~b}$ & 5,73 & $\mathrm{~b}$ \\
$\mathrm{~B}$ & Dosis rekomendasi & 1,93 & 8,87 & $\mathrm{a}$ & 10,93 & $\mathrm{a}$ & 11,40 & $\mathrm{a}$ \\
$\mathrm{C}$ & Dosis rekomendasi+2.5 g/l KN & 2,33 & 8,8 & $\mathrm{a}$ & 10,67 & $\mathrm{a}$ & 11,13 & $\mathrm{a}$ \\
$\mathrm{D}$ & Dosis rekomendasi+5 g/l KN & 1,73 & 8,53 & $\mathrm{a}$ & 10,00 & $\mathrm{a}$ & 10,53 & $\mathrm{a}$ \\
$\mathrm{E}$ & Dosis rekomendasi+10 g/l KN & 2,27 & 8,27 & $\mathrm{a}$ & 10,27 & $\mathrm{a}$ & 11,00 & $\mathrm{a}$ \\
$\mathrm{F}$ & 3/4 Dosis rekomendasi+5 g/l KN & 1,73 & 4,07 & $\mathrm{~b}$ & 6,33 & $\mathrm{~b}$ & 7,00 & $\mathrm{~b}$ \\
$\mathrm{G}$ & 1/2 Dosis rekomendasi+5 g/l KN & 2,13 & 4,00 & $\mathrm{~b}$ & 4,93 & $\mathrm{~b}$ & 5,40 & $\mathrm{~b}$ \\
$\mathrm{H}$ & 1/4 Dosis rekomendasi+5 g/l KN & 1,80 & 4,13 & $\mathrm{~b}$ & 5,07 & $\mathrm{~b}$ & 5,60 & $\mathrm{~b}$ \\
$\mathrm{~J}$ & 2 x Dosis rekomendasi+5 g/l KN & 1,67 & 8,60 & $\mathrm{a}$ & 10,53 & $\mathrm{a}$ & 11,13 & $\mathrm{a}$ \\
\hline
\end{tabular}

Keterangan: $\mathrm{KN}=$ kalsium nitrat

Angka yang diikuti oleh huruf yang sama pada kolom yang sama tidak berbeda nyata pada uji BNJ 5\%

\section{Diameter umbi}

Perlakuan pupuk anorganik kalsium nitrat menunjukkan pengaruh yang nyata terhadap diameter umbi. 0 menunjukkan bahwa pupuk anorganik kalsium nitrat dosis $5 \mathrm{~g} / \mathrm{l}$ dapat mengoptimalkan diameter tanaman meskipun dosis pupuk $\mathrm{N}$ berupa urea dan ZA diberikan sebanyak 3/4 dari dosis rekomendasi. Hal ini menunjukkan bahwa pemberian pupuk anorganik kalsium nitrat dapat menjadi pupuk pelengkap cair yang meningkatkan efisiensi penggunaan urea dan ZA untuk meningkatkan diameter umbi meskipun dosis $\mathrm{N}$ yang diberikan ke dalam tanah berkurang sebanyak 25\%. Hal ini dikarenakan pengaruh kalium yang dapat meningkatkan diameter umbi pada dosis tertentu (Gunadi, 2009). 
Tabel 5. Pengaruh Pupuk Anorganik Kalsium Nitrat Terhadap Diameter Umbi

\begin{tabular}{|c|c|c|c|}
\hline \multirow{2}{*}{$\frac{\text { Kode }}{\text { A }}$} & \multirow[t]{2}{*}{ Perlakuan } & \multicolumn{2}{|c|}{$\begin{array}{l}\text { Diameter } \\
(\mathrm{cm})\end{array}$} \\
\hline & & 1,07 & $\mathrm{~cd}$ \\
\hline B & Dosis rekomendasi & 1,70 & abcd \\
\hline $\mathrm{C}$ & Dosis rekomendasi $+2.5 \mathrm{~g} / 1 \mathrm{KN}$ & 1,87 & $a b c$ \\
\hline $\mathrm{D}$ & Dosis rekomendasi+5 $\mathrm{g} / \mathrm{l} \mathrm{KN}$ & 2,07 & $\mathrm{a}$ \\
\hline $\mathrm{E}$ & Dosis rekomendasi $+10 \mathrm{~g} / \mathrm{KN}$ & 2,10 & a \\
\hline $\mathrm{F}$ & 3/4 Dosis rekomendasi $+5 \mathrm{~g} / \mathrm{l} \mathrm{KN}$ & 1,90 & $a b c$ \\
\hline G & 1/2 Dosis rekomendasi $+5 \mathrm{~g} / \mathrm{KN}$ & 1,00 & $\mathrm{~d}$ \\
\hline $\mathrm{H}$ & 1/4 Dosis rekomendasi+5 g/l KN & 1,10 & bcd \\
\hline $\mathrm{J}$ & $2 \times$ Dosis rekomendasi $+5 \mathrm{~g} / \mathrm{l} \mathrm{KN}$ & 1,93 & $\mathrm{ab}$ \\
\hline
\end{tabular}

Keterangan: $\mathrm{KN}=$ kalsium nitrat

Angka yang diikuti oleh huruf yang sama pada kolom yang sama tidak berbeda nyata pada uji BNJ 5\%

\section{Bobot Basah, Bobot Kering dan Susut Bobot Umbi Per Rumpun}

Perlakuan
menunjukkan pengaruh yang nyata
terhadap bobot basah per rumpun dan
bobot kering per rumpun. 0
menunjukkan bahwa bobot basah
perlakuan 5 g/l kalsium nitrat
ditambah $3 / 4$ dosis rekomendasi lebih
rendah daripada dosis rekomendasi
padahal bobot kering pada kedua
perlakuan tersebut sama. Hal tersebut
dikarenakan susut bobot umbi pada
perlakuan dosis rekomendasi yang
tinggi (22,15\%) sedangkan pada
perlakuan F hanya 17,39\% (0).
Susut bobot pada dosis
rekomendasi yang ditambahkan pupuk

anorganik kalsium nitrat 2,5 g/l atau 5 $\mathrm{g} / \mathrm{l}$ memiliki susut bobot umbi lebih rendah dibandingkan dengan kontrol (0). Hal ini menunjukkan bahwa dengan penambahan pupuk anorganik kalsium nitrat mampu meningkatkan bobot massa kering umbi dibandingkan dengan massa airnya sehingga mengurangi penyusutan bobot umbi saat proses pengeringan. Hal ini dikarenakan adanya tambahan pupuk kalium melalui daun. Penggunaan pupuk kalium pada daun dapat meningkatkan kualitas umbi (Utomo dan Suprianto, 2019). 
Tabel 6. Pengaruh Pupuk Anorganik Kalsium Nitrat terhadap Bobot Basah per Rumpun dan Bobot Kering per Rumpun

\begin{tabular}{clrlll}
\hline Kode & \multicolumn{1}{c}{ Perlakuan } & \multicolumn{2}{c}{$\begin{array}{c}\text { Bobot Basah } \\
\text { Umbi Per } \\
\text { Rumpun }(\mathrm{g})\end{array}$} & $\begin{array}{c}\text { Bobot Kering } \\
\text { Umbi Per } \\
\text { Rumpun }(\mathrm{g})\end{array}$ \\
\hline $\mathrm{A}$ & Kontrol & 18,67 & $\mathrm{c}$ & 13,33 & $\mathrm{c}$ \\
$\mathrm{B}$ & Dosis rekomendasi & 66,67 & $\mathrm{a}$ & 52,00 & $\mathrm{ab}$ \\
$\mathrm{C}$ & Dosis rekomendasi+2.5 g/l KN & 72,00 & $\mathrm{a}$ & 59,67 & $\mathrm{a}$ \\
$\mathrm{D}$ & Dosis rekomendasi+5 g/l KN & 70,00 & $\mathrm{a}$ & 58,33 & $\mathrm{a}$ \\
$\mathrm{E}$ & Dosis rekomendasi+10 g/l KN & 72,00 & $\mathrm{a}$ & 59,33 & $\mathrm{a}$ \\
$\mathrm{F}$ & 3/4 Dosis rekomendasi+5 g/l KN & 48,33 & $\mathrm{~b}$ & 39,67 & $\mathrm{~b}$ \\
$\mathrm{G}$ & 1/2 Dosis rekomendasi+5 g/l KN & 20,67 & $\mathrm{c}$ & $17,33 \quad \mathrm{c}$ \\
$\mathrm{H}$ & 1/4 Dosis rekomendasi+5 g/l KN & 18,67 & $\mathrm{c}$ & $15,33 \quad \mathrm{c}$ \\
$\mathrm{J}$ & 2 x Dosis rekomendasi+5 g/l KN & 79,33 & $\mathrm{a}$ & 49,67 & $\mathrm{ab}$ \\
\hline
\end{tabular}

Keterangan: $\mathrm{KN}=$ kalsium nitrat

Angka yang diikuti oleh huruf yang sama pada kolom yang sama tidak berbeda nyata pada uji BNJ 5\%

Tabel 7. Pengaruh Pupuk Anorganik Kalsium Nitrat terhadap Susut Bobot Umbi

\begin{tabular}{|c|c|c|c|}
\hline Kode & Perlakuan & $\begin{array}{r}\text { Susut B } \\
(\%)\end{array}$ & \\
\hline A & Kontrol & 28,75 & $a b$ \\
\hline B & Dosis rekomendasi & 22,15 & $\mathrm{bc}$ \\
\hline $\mathrm{C}$ & Dosis rekomendasi $+2.5 \mathrm{~g} / \mathrm{KN}$ & 17,06 & $\mathrm{c}$ \\
\hline $\mathrm{D}$ & Dosis rekomendasi+5 $\mathrm{g} / \mathrm{l} \mathrm{KN}$ & 16,66 & $\mathrm{c}$ \\
\hline $\mathrm{E}$ & Dosis rekomendasi+10 g/l KN & 17,39 & $\mathrm{bc}$ \\
\hline $\mathrm{F}$ & 3/4 Dosis rekomendasi $+5 \mathrm{~g} / \mathrm{l} \mathrm{KN}$ & 17,96 & $\mathrm{bc}$ \\
\hline G & 1/2 Dosis rekomendasi $+5 \mathrm{~g} / \mathrm{l} \mathrm{KN}$ & 16,60 & $\mathrm{c}$ \\
\hline $\mathrm{H}$ & 1/4 Dosis rekomendasi $+5 \mathrm{~g} / \mathrm{l} \mathrm{KN}$ & 17,46 & $\mathrm{bc}$ \\
\hline $\mathrm{J}$ & $2 \times$ Dosis rekomendasi $+5 \mathrm{~g} / 1 \mathrm{KN}$ & 37,22 & $\mathrm{a}$ \\
\hline
\end{tabular}

Keterangan: $\mathrm{KN}=$ kalsium nitrat

Angka yang diikuti oleh huruf yang sama pada kolom yang sama tidak berbeda nyata pada uji BNJ $5 \%$

\section{Hasil Panen}

Analisa data menunjukkan bahwa hasil panen dipengaruhi oleh seluruh perlakuan yang diberikan. Penggunaan pupuk anorganik kalsium nitrat $5 \mathrm{~g} / 1$ pada $3 / 4$ dosis rekomendasi memiliki produksi yang sama dengan dosis rekomendasi. Hal ini menunjukkan dengan pemberian pupuk anorganik kalsium nitrat $5 \mathrm{~g} / \mathrm{l}$ mampu menghemat pupuk Urea dan ZA sebesar 25\%. Pupuk anorganik 
kalsium nitrat memiliki kandungan utama nitrogen berupa nitrat dapat menambah suplai unsur N. Suplai N dari pupuk kalsium nitrat yang $\begin{array}{llll}\text { ditambahkan } & \text { sebanyak } & 3 / 4 & \text { dosis }\end{array}$ rekomendasi mempengaruhi variabel tinggi tanaman, diameter umbi, berat basah, berat kering dan susut bobot yang menyamai dengan dosis rekomendasi sehingga hasil produksi bawang merah dapat menyamai dengan dosis rekomendasi.

Tabel 8. Pengaruh Pupuk Anorganik Kalsium Nitrat terhadap Hasil Bawang Merah

Keterangan: $\overline{\mathrm{KN}}=$ kalsium nitrat

\begin{tabular}{|c|c|c|c|}
\hline Kode & Perlakuan & Hasil (t/ha & \\
\hline A & Kontrol & 3,45 & $\mathrm{c}$ \\
\hline B & Dosis rekomendasi & 13,26 & $a b$ \\
\hline $\mathrm{C}$ & Dosis rekomendasi+2.5 g/l KN & 15,33 & $\mathrm{a}$ \\
\hline $\mathrm{D}$ & Dosis rekomendasi+5 g/l KN & 14,84 & $\mathrm{a}$ \\
\hline $\mathrm{E}$ & Dosis rekomendasi+10 g/l KN & 15,38 & $\mathrm{a}$ \\
\hline F & 3/4 Dosis rekomendasi+5 g/l KN & 10,12 & $\mathrm{~b}$ \\
\hline G & 1/2 Dosis rekomendasi+5 $\mathrm{g} / \mathrm{KN}$ & 4,45 & $\mathrm{c}$ \\
\hline $\mathrm{H}$ & 1/4 Dosis rekomendasi+5 g/l KN & 3,89 & $\mathrm{c}$ \\
\hline $\mathrm{J}$ & $2 \times$ Dosis rekomendasi $+5 \mathrm{~g} / 1 \mathrm{KN}$ & 12,98 & $a b$ \\
\hline
\end{tabular}

Angka yang diikuti oleh huruf yang sama pada kolom yang sama tidak berbeda nyata pada uji BNJ 5\%

\section{KESIMPULAN DAN SARAN}

\section{Kesimpulan}

Pupuk anorganik kalsium nitrat efektif meningkatkan pertumbuhan dan kualitas umbi tanaman bawang merah. Dosis $5 \mathrm{~g} / \mathrm{l} \mathrm{kalsium} \mathrm{nitrat} \mathrm{yang}$ ditambahkan dengan $150 \mathrm{~kg} / \mathrm{ha}$ urea dan $375 \mathrm{~kg} / \mathrm{ha} \mathrm{ZA}$ memberikan hasil yang optimal.

\section{Saran}

Perlu dilakukan penelitian pupuk anorganik kalsium nitrat tanpa pemberian nitrogen dari sumber pupuk anorganik lain.

\section{DAFTAR PUSTAKA}

Alexander, A., dan M. Schroeder. 1987. Modern Trends in Foliar Fertilization. J. Plant Nutr. 10 (916): 1391-1399. 
Barker, A. V. dan J. P. David. 2015. Nitrogen in Handbook of Plant Nutrition. CRC Press.

Baswarsiati, dan C. Tafakresnanto. 2019. Kajian Penerapan Good Agricultural Practices (GAP) Bawang Merah di Nganjuk dan Probolinggo. Agrika: Jurnal Ilmu-Ilmu Pertanian. 13 (2): 147-161.

Dianawati, M., S. Ilyas dan A. Susila. 2013. Produksi Umbi Mini Kentang Secara Aeroponik Melalui Penentuan Dosis Optimum Pupuk Daun Nitrogen.

Eviati, dan Sulaeman. 2009. Petunjuk Teknis Kimia tanah, Tanaman, Air dan Pupuk Edisi 2. Balai Penelitian Tanah. Bogor.

Gunadi, N. 2009. Kalium Sulfat dan Kalium Klorida Sebagai Sumber Pupuk Kalium pada Tanaman Bawang Merah. J. Hortik. 19 (2): 174-185.

Kurniasih, R., A. Wibowo dan S.N.H. Utami. 2017. Pengaruh Dosis Pupuk Urea terhadap Kandungan $\mathrm{N}$ Tanah, Serapan $\mathrm{N}$ dan Hasil Umbi Bawang Merah pada Tanah Steril dan Tanah Inokulasi Effect. J. Pertan. Presisi. 01 (01): 1-16.

Sinaga, P., Meiriani dan Y. Hasanah. 2014. Respons Pertumbuhan dan Produksi Kailan (Brassica oleraceae L.) pada Pemberian Berbagai Dosis Pupuk Organik Cair Paitan (Tithonia diversifolia (Hemsl.) Gray). J. Online
Agroteknologi. 2 (4): 1584-1588.

Sumarni, N. dan A. Hidayat. 2005. Budidaya Bawang Merah. Balai Penelitian Tanaman Sayuran. Bandung.

Sumarni, N., R. Rosliani dan R.S. Basuki. 2016. Respons Pertumbuhan, Hasil Umbi, dan Serapan Hara NPK Tanaman Bawang Merah terhadap Berbagai Dosis Pemupukan NPK pada Tanah Alluvial. Jurnal Hortikultura. 22 (4): 366-375.

Sumarni, N., R. Rosliani dan Suwandi. 2013. Optimasi Jarak Tanam dan Dosis Pupuk NPK untuk Produksi Bawang Merah dari Benih Umbi Mini di Dataran Tinggi. Jurnal Hortikultura. 22 (2): 147-154.

Suwandi, N., G.A. Sopha, L. Lukman, dan M.P. Yufdy. 2017. Efektivitas Pupuk Hayati Unggulan Nasional Terhadap Pertumbuhan dan Hasil Bawang Merah. J. Hortik. 27 (1): 23-34.

Utomo, P.S. dan A. Suprianto. 2019. Respon Pertumbuhan dan Produksi Tanaman Bawang Merah (Allium ascalonicum L.) Varietas Thailand terhadap Perlakuan Dosis Pupuk Kusuma Bioplus dan $\mathrm{KNO}_{3}$ Putih. J. Ilm. Hijau Cendekia. 4 (1): 28-33. 